\title{
Energy Conservation in Thiobacillus neapolitanus c: Sulphide and Sulphite Oxidation
}

\author{
By J. W. DROZD* \\ Department of Biochemistry, School of Biology, University of Leicester, \\ Leicester $\mathrm{LE}_{\mathrm{I}}{ }_{7} \mathrm{RH}$
}

(Received 14 June 1976)

INTRODUCTION

\begin{abstract}
The aerobic chemoautotroph Thiobacillus neapolitanus $\mathrm{C}$, when grown on thiosulphate, can couple thiosulphate oxidation to cytochrome $c$ reduction so there is one functional proton translocating loop (loop 3; Drozd, 1974) which indicates a maximal P/O ratio of I $\left(\rightarrow \mathrm{H}^{+} / \mathrm{O}\right.$ ratio of $2 \cdot 0$, i.e. 2 g-equiv. $\mathrm{H}^{+}$translocated outwards per g-atom oxygen consumed; Mitchell, I $966 a, b$ ) on the assumption that the $\rightarrow \mathrm{H}^{+} /$ATP ratio is 2 . Aleem (I975) reasoned from inhibitor studies that aerobic sulphide oxidation in $T$. neapolitanus was associated with two sites of oxidative phosphorylation, whereas sulphite oxidation, like that of thiosulphate, was probably only associated with one site. Both thiosulphate and sulphide oxidation can be used to drive pyridine nucleotide reduction in T. neapolitanus (Roth et al., 1973). This study uses the measurement of respiration-driven proton translocation (Mitchell, $\mathrm{I} 966 a, b)$ to indicate the $\mathrm{P} / \mathrm{O}$ ratio association with sulphide and sulphite oxidation.
\end{abstract}

\section{METHODS}

Batch growth of $T$. neapolitanus $\mathrm{c}$, and measurements of $\rightarrow \mathrm{H}^{+} / \mathrm{O}$ ratios and of respiration (in $50 \mathrm{~mm}$-Tris/HCl, $\mathrm{pH} 7^{\circ}$ ) ) have been described previously (Drozd, 1974 ). The apparent $K_{\mathrm{m}}$ and maximum oxidation velocity for substrate were measured from the oxygen uptake rates of the bacteria (corrected for endogenous respiration) with various concentrations of added substrate (Harrison, 1973). Valinomycin and carbonylcyanide- $m$-chlorophenylhydrazone (both from Sigma) were prepared as $0.5 \mathrm{mg} \mathrm{ml}^{-1}$ and $5 \mathrm{~mm}$ solutions in ethanol respectively. Sodium sulphide (Hopkin and Williams, Swansea; recrystallized) and sodium sulphite (BDH, Analar grade) solutions were freshly prepared every $2 \mathrm{~h}$, adjusted to approx. $\mathrm{pH} 7 \cdot 0$, and stored on ice under nitrogen. Cytochrome $c$ reduction was measured at room temperature in a Pye Unicam SP I80o spectrophotometer at $552 \mathrm{~nm}$. The prepared cell suspension (Drozd, 1974) was aerated vigorously on a vortex mixer. The substrate was added to cell suspension in the sample cuvette and the steady. state increase in absorbance was noted. When all the oxygen had been utilized there was a further increase in absorbance to the anaerobic steady-state level. The addition of a few crystals of sodium dithionite to the sample cuvette gave a further increase in absorbance due to complete cytochrome(s) $c$ reduction. As a check, dithionite was then added to the reference (oxidized) cuvette to see if the original (oxidized/oxidized) absorbance reading was obtained. Cell biomass was estimated by measuring total carbon (Beckman 915 Total Organic Carbon Analyser) and converting to dry weight on the assumption that the dried cells were $46 \%$ carbon.

\footnotetext{
* Present address: Shell Biosciences Laboratory, Shell Research Ltd, Sittingbourne, Kent, ME9 8AG.
} 


\section{Table I. Respiration-driven proton translocation and substrate oxidation in intact cells of $T$. neapolitanus $\mathrm{C}$}

The $K_{\mathrm{m}}$ for substrate oxidation and the maximum velocity of oxidation were determined on washed, intact, unstarved cells of $T$. neapolitanus $\mathrm{C}$ in $50 \mathrm{mM}$-Tris $/ \mathrm{HCl}$ buffer, $\mathrm{pH} 7.0$, at $30^{\circ} \mathrm{C}$ by measuring $\mathrm{O}_{2}$ uptake in a Rank oxygen electrode (Rank, Bottisham, Cambridgeshire) as described in Methods. Extrapolated $\rightarrow \mathrm{H}^{+} / \mathrm{O}$ ratios were measured on the unstarved cells at $\mathrm{pH} 6 \cdot 8$ to 7.2 in the presence of $70 \mathrm{~mm}$-potassium thiocyanate as described in the Methods. (Values are given \pm S.E.M., with the number of observations in parentheses.)

\begin{tabular}{|c|c|c|c|c|}
\hline Substrate & $\begin{array}{l}\text { Maximum oxidation } \\
\text { velocity [mmol } \mathrm{O}_{2} \\
\left.(\mathrm{~g} \text { dry wt })^{-1} \mathrm{~h}^{-1}\right]\end{array}$ & $K_{\mathrm{m}}(\mu \mathrm{M})$ & $\begin{array}{l}\text { Final concn }(\mathrm{mm}) \\
\text { of substrate in } \\
\rightarrow \mathrm{H}^{+} / \mathrm{O} \text { assay }\end{array}$ & $\begin{array}{c}\quad \rightarrow \mathrm{H}^{+} / \mathrm{O} \\
\text { (g-equiv. } \mathrm{H}^{+} \\
\text {per g-atom } \mathrm{O} \text { ) }\end{array}$ \\
\hline Sodium sulphite & 6 & $47 \pm I \cdot 2(4)$ & $\begin{array}{l}0.5 \\
1.0\end{array}$ & $\begin{array}{l}I \cdot 7 \pm 0 \cdot I(6) \\
I \cdot 4 \pm 0 \cdot I(4)\end{array}$ \\
\hline Sodium sulphide & 15 & $60.4 \pm 9.9$ & $\begin{array}{l}0.5 \\
I \cdot 0\end{array}$ & $\begin{array}{l}I \cdot 5 \pm 0 \cdot I(6) \\
I \cdot 6 \pm 0 \cdot I(4)\end{array}$ \\
\hline Sodium thiosulphate & 9 & $13 \cdot 5 \pm I \cdot 8(6)$ & - & $*$ \\
\hline
\end{tabular}

* Values are given by Drozd (1974).

\section{RESULTS}

Intact, washed cells of thiosulphate-grown $T$. neapolitanus $\mathrm{C}$ oxidized sodium thiosulphate, sulphite and sulphide (Table r) at the given maximum rates and apparent $K_{\mathrm{m}}$ values for the substrate. Sodium sulphite or sulphide did not cause any oxygen uptake in the absence of bacteria.

In the aerobic steady-state, added sodium sulphite and sodium sulphide (both at $500 \mu \mathrm{M}$ ) gave an apparent $55 \%$ and $73 \%$ reduction of cytochrome $c$. In the anaerobic steady-state the values were $80 \%$ and $85 \%$. The measurement of respiration-driven proton translocation indicated that with endogenous substrate, sulphite or sulphide the maximum $\rightarrow \mathrm{H}^{+} / \mathrm{O}$ value never exceeded $2 \cdot 0$, which corresponds to a maximum $\mathrm{P} / \mathrm{O}$ ratio of I (on the assumption that the $\rightarrow \mathrm{H}^{+} / \mathrm{P}$ ratio is $2 \cdot 0$ ). Addition of sodium sulphide to above $2.5 \mathrm{~mm}$ caused no pulses to be formed, although in the oxygen electrode respiration was unaffected by this concentration. Likewise, experiments in which bacteria were starved of endogenous substrate (Jones et al., 1975) and then loaded with $0 \cdot \mathrm{I}$ to I.O mM sodium sulphite or sodium sulphide did not give $\rightarrow \mathrm{H}^{+} / \mathrm{O}$ ratios in excess of 2 . The addition of valinomycin to a final concentration of $2 \cdot 0 \mu \mathrm{g} \mathrm{ml}^{-1}$ did not markedly affect the extrapolated $\rightarrow \mathrm{H}^{+} / \mathrm{O}$ ratios but the addition of the uncoupling agent carbonylcyanide- $m$-chlorophenylhydrazone to a final concentration of $5 \mu \mathrm{M}$ caused a rapid collapse of the $\mathrm{pH}$ gradient. Rotenone $(350 \mu \mathrm{M})$ caused no increase in the $\rightarrow \mathrm{H}^{+} / \mathrm{O}$ ratios in the presence of sulphide or sulphite.

\section{DISCUSSION}

The results indicate that, like thiosulphate oxidation, both sulphite and sulphide oxidation are associated with a maximal $\rightarrow \mathrm{H}^{+} / \mathrm{O}$ ratio slightly under $2 \cdot 0$, i.e. a maximal $\mathrm{P} / \mathrm{O}$ ratio of 0.8 to 0.9 . This low $\mathrm{P} / \mathrm{O}$ ratio associated with sulphide oxidation is surprising because sulphide is a relatively strong reductant and thermodynamically one might expect a $\mathrm{P} / \mathrm{O}$ ratio of at least 2 (Aleem, 1975). Sodium sulphide is slowly oxidized under aerobic conditions; the rate of oxidation is increased in the presence of iron-containing compounds (Trudinger 1969) so that the identity of the substrates with sulphide oxidation is unclear. Steady-state cytochrome $c$ reduction is greater with sulphide than with sulphite or thio- 
sulphate but this might indicate that sulphide has caused some non-specific reduction of ironcontaining redox couples within the cell or that there is merely a greater rate of electron flux through the respiratory chain (Chance, 1957). The effect of rotenone on electron transport is unknown because with thiosulphate as substrate it slightly increased the $\rightarrow \mathrm{H}^{+} / \mathrm{O}$ ratios (Drozd, 1974). An inhibition of reverse electron flow by rotenone should not increase the extrapolated $\rightarrow \mathrm{H}^{+} / \mathrm{O}$ ratios and only the rate of decay of the proton gradient might be affected by an energy-dependent reverse electron flow.

From the above results and the continuous-culture growth yield data for thiosulphatelimited cultures of $T$. neapolitanus (Hempfling \& Vishniac, 1967), the calculated maximum $Y^{\mathrm{ATP}}$, corrected for maintenance, is $5^{\circ} \mathrm{O}$ on the assumption that there is maximally one site of oxidative phosphorylation associated with substrate oxidation. With one additional phosphorylation (substrate level) per mol thiosulphate oxidized via the formation of adenosine $5^{\prime}$-phosphosulphate (Peck, 1962), the maximum $Y^{\mathrm{ATP}}$ is 3.7 . This is similar to the value of 3.0 calculated by Rittenberg (1972) from the same data, but is somewhat less than the theoretical maximum values of the $Y^{\mathrm{ATP}}$ for chemoautotrophic growth of 7.9 calculated by Hempfling \& Vishniac (1973) and of 4.85 by Stouthamer \& Bettenhaussen (1973). There is little data available for the yields of other chemoautotrophs in continuous culture. For Hydrogenomonas eutropha HI6 (now Alcaligenes eutrophus HI6) grown autotrophically in continuous culture under oxygen limitation with hydrogen as the energy source, Schuster \& Schlegel (1967) calculated a maximum $Y^{\mathrm{ATP}}$ (corrected for maintenance) of $1 \cdot 7$ when the $\mathrm{P} / \mathrm{O}$ ratio was taken to be 3 . This $\mathrm{P} / \mathrm{O}$ ratio was partially confirmed by the $\rightarrow \mathrm{H}^{+} / \mathrm{O}$ ratio of 7.88 obtained by Beatrice \& Chappell (I974), which indicated three sites of oxidative phosphorylation and an energy-linked, proton-translocating NADPH $\longrightarrow$ $\mathrm{NAD}^{+}$transhydrogenase.

Finally, it is unlikely that energy can be generated between cytochrome $c$ and the respiratory nitrate reductase in Thiobacillus denitrificans grown with $\mathrm{NO}_{3}{ }^{-}$as the terminal electron acceptor, as is also the case with the cytochrome $c$ containing aerobic bacteria Pseudomonas denitrificans (Koike \& Hattori, 1975a, b) and Alcaligenes eutrophus HI6 (Drozd \& Jones, unpublished). Either all the ATP is generated by substrate level phosphorylation (via the adenosine $5^{\prime}$-phosphosulphate system) or, as suggested by Aleem (1975), there is a split of thiosulphate to sulphite and sulphide with the oxidation of sulphide via a flavin $\longrightarrow$ cytochrome $c$ system such that one ATP is generated between the flavin and cytochrome c. Thus, under anaerobic conditions, sulphide oxidation may be associated with energy coupling before cytochrome(s) $c$ as suggested by Aminuddin \& Nicholas (1973, 1974) and Aleem (1975).

I would like to thank Professor D. P. Kelly for the original culture and Dr C. W. Jones for useful discussions.

\section{REFERENCES}

Aminuddin, M. \& Nicholas, D. J. D. (1973). Sulphide oxidation linked to the reduction of nitrate and nitrite in Thiobacillus denitrificans. Biochimica et biophysica acta 325, 8I-93.

Aminuddin, M. \& Nicholas, D. J. D. (1974). Electron transfer during sulphide and sulphite oxidation in Thiobacillus denitrificans. Journal of General Microbiology 82, I I 5-I 23.

AleEM, M. I. H. (I975). Biochemical reaction mechanisms in sulfur oxidation by chemosynthetic bacteria. Plant and Soil 43, 587-607.

BeAtrice, M. C. \& Chappell, J. B. (1974). Respiration-driven proten translocation in Hydrogenomonas eutropha HI6. Biochemical Society Transactions 2, I5I-I53.

Chance, B. (1 957). Cellular oxygen requirements. Federation Proceedings 16, 671-680.

Drozd, J. W. (1974). Respiration-driven proton translocation in Thiobacillus neapolitanus C. FEBS Letters 49, $103-105$. 
Harrison, D. E. F. (1973). Studies on the affinity of methanol and methane utilising bacteria for their carbon substrates. Journal of Applied Bacteriology 36, 30I-308.

HempFling, W. P. \& VIsHNIAC, W. (1967). Yield coefficients of Thiobacillus neapolitanus in continuous culture. Journal of Bacteriology 93, 874-878.

Jones, C. W., BRICE, J. M., Downs, A. J. \& Drozd, J. W. (1975). Bacterial respiration-linked proton translocation and its relationship to respiratory chain composition. European Journal of Biochemistry 52 , 265-27I.

KoIKE, I. \& HATTORI, A. (1975 $a$ ). Growth yield of a denitrifying bacterium, $P_{\text {seudomonas denitrificans, under }}$ aerobic and denitrifying conditions. Journal of General Microbiology 88, I-Io.

KoIKE, I. \& HATTORI, A. (I975 b). Energy yield of denitrification. An estimate from growth yield in con-

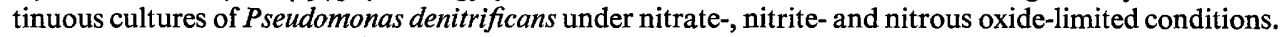
Journal of General Microbiology 88, II-19.

MrtcheLl, P.(1966a). Chemiosmotic Coupling in Oxidative and Photosynthetic Phosphorylation. Bodmin, Cornwall: Glynn Research.

MitcheLl, P. (1966 b). Chemiosmotic coupling in oxidative and photosynthetic phosphorylation. Biological Reviews 4I, 445-502.

PECK, H. D., Jr (I962). Comparative metabolism of inorganic sulfur compounds in micro-organisms. Bacteriological Reviews 26, 67-94

RitTENBeRG, S. C. (1972). The obligate autotroph - the demise of a concept. Antonie van Leeuwenhoek $\mathbf{3}^{8}$, 457-478.

Roth, C. W., Hempfling, W. P., Connors, J. N. \& Vishniac, W. (I973). Thiosulfate- and sulfidedependent pyridine nucleotide reduction and gluconeogenesis in intact Thiobacillus neapolitanus. Journal of Bacteriology II4, 592-599.

SChUSTER, E. \& SChLEGel, H. G. (1967). Chemolithotrophes Wachstum von Hydrogenomonas hi6 in Chemostaten mit elektrolytischer Knallgaserzeugung. Archiv für Mikrobiologie 58, 380-409.

Stouthamer, A. H. \& Bettenhaussen, C. (1973). Utilization of energy for growth and maintenance in continuous and batch cultures of micro-organisms. Biochimica et biophysica acta 301, 53-70.

TrUDINGER, P. A. (1969). Assimilatory and dissimilatory metabolism of inorganic sulphur compounds. Advances in Microbial Physiology 3, I I I-I 52. 